\title{
Pontos negativos na visão dos residentes sobre a aprendizagem dos conteúdos antropológicos e sociais a partir do uso de metodologias ativas de ensino- aprendizagem
}

Tarsila Teixeira Vilhena Lopes, Leonardo Carnut, Lúcia Dias da Silva Guerra, Celso Zilbovicius, Afonso Luís Puig Pereira

\section{Resumo}

Introdução: No estudo da Sociologia e Antropologia da Saúde, os residentes são convidados a identificarem os conceitos fundamentais da Sociologia e da Antropologia que os ajudam a compreender a Saúde enquanto fenômeno social. Nesse sentido, espera-se sempre trabalhar de forma introdutória alguns temas como: a relação entre a Sociologia e Antropologia enquanto Ciências Sociais e sua importância para a saúde; a virada paradigmática da compreensão do conhecimento em saúde e suas repercussões para a prática sanitária; o uso dos conceitos sociológicos e antropológicos fundamentais para o estudo das práticas em saúde; e, por fim, o exercício da visão/pensamento socioantropológico sobre saúde no cotidiano da vida em coletividade. No entanto, dotar esses conteúdos de sentido para profissionais na área da saúde é uma tarefa hercúlea, já que os egressos dos cursos de saúde ainda são colonizados por uma ótica biomédica. Essa ótica deriva um modo de raciocínio linear, hipotético-dedutivo que, os profissionais de saúde, quando se preocupam em considerar os elementos humanístico-sociais em suas análises, na melhor das hipóteses promovem uma leitura do 'social' como 'fatores' de risco ou 'variáveis' independentes. Esse entendimento, por mais que seja louvável, ainda é pouco producente na compreensão do 'social', pois desconsidera sua característica de totalidade e inverte a relação 'contém/está-contido' essencial para discutir a saúde enquanto fenômeno socialmente determinado. Por isso, acredita-se que as metodologias ativas de aprendizagem podem ser um método mais viável para desconstrução da forma de raciocínio biomédico e proporcionar a elaboração de um pensamento crítico-reflexivo que ultrapasse as fronteiras da linearidade e que possa alcançar níveis de abstração mais altos. No entanto, por mais que essa metodologia pareça ser a mais adequada para garantir a aprendizagem de conteúdos sociais, é sabido que nem todos os estudantes se adequam as metodologias ativas da mesma maneira gerando com isso a necessidade de mapear quais são os principais pontos negativos na experiência com metodologias ativas quando estas são utilizadas para o processo de ensino-aprendizagem de conteúdos humanístico-sociais. Objetivo: Assim, este estudo visou descrever os pontos negativos na visão dos residentes sobre a aprendizagem dos conteúdos antropológicos e sociais a partir do uso de metodologias ativas de ensino- aprendizagem. A intenção dessa pesquisa foi traçar um diagnóstico inicial da introdução das metodologias ativas considerando a Residência Multiprofissional como cenário de pluralidade de perfis que proporciona desafios na aprendizagem desses conteúdos por congregar profissões de repertório teórico e conceitual bastante distintos. Percurso Metodológico: Para tanto, desenhou-se um percurso metodológico baseado em uma pesquisa-ação, qualiquantitativa, com foco na investigação de percepção vivencial dos discentes sobre uma estratégia didática adotada. O cenário pedagógico foi o módulo de 'Sociologia e Antropologia da Saúde', com carga horária total de 24 horas, ministrada na Residência Multiprofissional em Saúde Coletiva (com ênfase em Gestão de Redes de Atenção à Saúde) da Universidade de Pernambuco (UPE) em outubro de 2015 e tendo quarenta e cinco (45) estudantes como sujeitos partícipes dessa atividade. Ao decorrer do módulo, os residentes trabalharam os conteúdos através de uma abordagem pedagógica mista, baseada na mescla de 
ISSN 2179-6750

diversos métodos ativos, incluindo tempestade de ideias, leituras coletivas, questões norteadoras, mapas conceituais, fichamentos coletivos e seminários dialogados. Ao final do módulo, realizou-se uma entrevista não-estruturada com os estudantes sobre a experiência vivenciada com a finalidade de captar a percepção dos residentes sobre os pontos negativos que eles identificaram na metodologias utilizadas. Pediu-se aos residentes que dissertassem sobre o seguinte tópico: "Coloque os pontos negativos que você percebe no módulo e na sua condução pelo professor" e os estudantes produziram textos em resposta a essa demanda de forma livre e aberta. A partir dos textos elaborados pelos estudantes, analisou-se o material produzido através da Análise de Conteúdo Clássica, do tipo Análise Frequencial (com uso de 'proposições' como Unidades Textuais (UT) de análise) e elegendo como suporte comparativo a experiência empírica já sistematizada por Anjos e colaboradores (2013) sobre a percepção de estudantes sobre o uso de metodologias ativas. Resultados: Decompôs-se os textos produzidos pelos estudantes em 114 Unidades de Texto (UT) (114 proposições) que puderam ser categorizadas em 16 áreas temáticas de significados correlatos construídas através de aproximação léxico-semântica. Por ordem de frequência no decorrer dos textos, foi possível identificar que as temáticas se organizam nas seguintes categorias: "Leituras de textos extensos e pouco tempo" 23,68\% (27); "Falta de uma aula introdutória" 10,52\% (12); "Dificuldades com a metodologia" 7,89\% (9); "Repetição de estratégias didáticas" 7,89\% (9); "Conversas/Poucas participações de alguns integrantes" 7,01\% (8); "Não identificou pontos negativos" 7,01\% (8); "Pouco tempo para a execução do módulo" 7,01\% (8); "Grandes quantidades de textos utilizados" 6,14\% (7); "Pouco tempo das atividades exigidas" 6,14\% (7); "Carga horária do módulo era pequena" 4,38\% (5); "Cansativo" 3,50\% (4); "Falta de recursos audiovisuais" 2,63\% (3); "Textos disponibilizados para leitura na hora da aula" 2,63\% (3); "Textos não relacionados com a saúde" 1,75\% (2); "Poucas dinâmicas nos grupos realizados" 0,87\% (1); "Foi muito estressante" 0,87\% (1). Conclusões: Grande parte dos conteúdos identificados nos textos dos estudantes apontam para o fato de que as leituras de textos que contém conteúdos antropológicos e sociais são extensos e lhes faltam tampo para esta leitura, sugerindo que o trabalho de leitura de outra área específica geram-lhes um incômodo e que pode ser melhor trabalhado com a disponibilidade de tempo maior para esta atividade. A falta de uma aula introdutória também pôde ser identificada como um ponto negativo cujo blended de metodologias ativas não deu conta. Foi possível identificar que grande parte dos conteúdos dos textos dos estudantes relatam quesitos atitudinais em relação ao estranhamento com a metodologia ativa e que transcendem a questão dos conteúdos da disciplina, tais quais: o cansaço, o estresse, a carga horária, e a disponibilidade dos textos. Assim, nesse contexto, pode-se dizer que os principais pontos negativos do uso das metodologias ativas para aprendizagem de conteúdos antropológicos e sociológicos se restringem mais ao conteúdo das ciências sociais do que necessariamente ao uso da metodologia ativa, sendo possível admitir que a metodologias ativas podem ser encaradas como um método que ajuda na compreensão do conteúdos socioantropológicos mesmo sob suas limitações de ordem operacional.

Descritores: Internato e Residência, Ensino, Educação Superior, Humanidades 